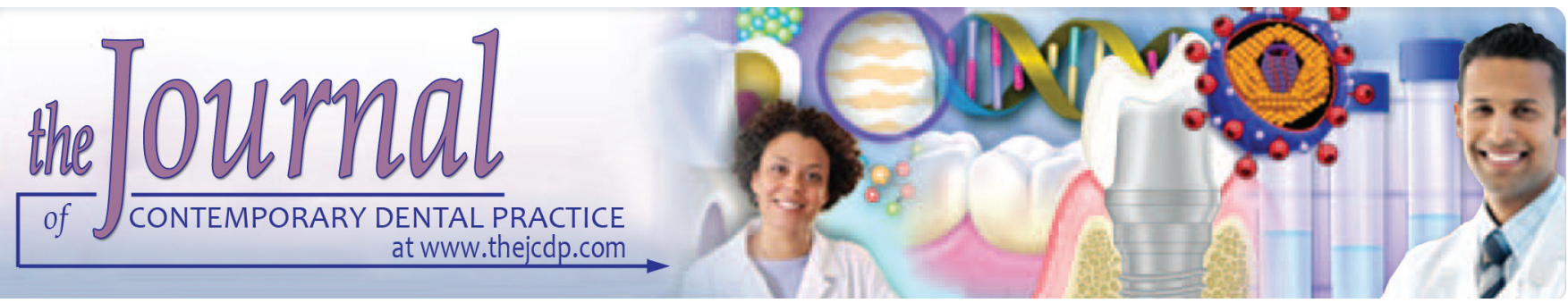

\title{
Prevalence, Location, and Size of Maxillary Sinus Septa: Computed Tomography Scan Analysis
}

\author{
${ }^{1}$ Ferial Taleghani, ${ }^{2}$ Maryam Tehranchi, ${ }^{3}$ Shahryar Shahab, ${ }^{4}$ Zahra Zohri
}

\begin{abstract}
Introduction: The present study was undertaken to evaluate the anatomy of the maxillary sinus in relation to its position and the height of its septa, using cone beam computed tomography (CBCT).

Materials and methods: In this descriptive retrospective study, 300 CBCT images of maxillary sinuses of patients with posterior maxillary edentulism were evaluated. The maxillary sinus septa were evaluated in relation to their prevalence, height, and position; t-test and Mann-Whitney tests were used for the analysis of data.
\end{abstract}

Results: Sinus septa were detected in $44 \%$ of the subjects, with equal frequencies in the anterior, middle, and posterior positions. The mean height of the septa was $3.6 \pm 1.56 \mathrm{~mm}$.

Conclusion: In a population of Iranian subjects, in half of the cases, the sinus septa might be present in the anterior, middle, and posterior positions.

Clinical significance: In order to avoid intraoperative problems during sinus lift procedures, it is necessary to accurately evaluate the sinus, preferably with the use of CBCT.

Keywords: Cone beam computed tomography, Dental implant, Maxillary sinus septa.

How to cite this article: Taleghani F, Tehranchi M, Shahab S, Zohri Z. Prevalence, Location, and Size of Maxillary Sinus Septa: Computed Tomography Scan Analysis. J Contemp Dent Pract 2017;18(1):11-15.

Source of support: Nil

Conflict of interest: None

1,2,4 Department of Periodontics, School of Dentistry, Shahed University, Tehran, Iran

${ }^{3}$ Department of Radiology, School of Dentistry, Shahed University, Tehran, Iran

Corresponding Author: Maryam Tehranchi, Department of Periodontics, School of Dentistry, Shahed University, Tehran Iran, Phone: +982188959210, e-mail: mrym_tehranchi@yahoo. com

\section{INTRODUCTION}

Currently, sinus lift procedures using the lateral window technique are a safe and predictable method for the reconstruction of atrophic posterior maxilla for placing implants; however, it is a sensitive technique and requires surgical expertise of the surgeons. ${ }^{1}$ A lack of accurate knowledge about the anatomy of the maxillary sinus before the sinus lift procedure might result in intraoperative problems. ${ }^{2}$ Perforation of the Schneiderian membrane is the chief intraoperative complication, occurring in 11 to $56 \%$ of sinus lift procedures. ${ }^{3}$ The presence of septa increases the risk of perforation of the membrane. The maxillary sinus septa were first described by Underwood in $1910 .{ }^{4}$ Septa are partitions of the cortical bone and are found in the form of an inverted gothic arch, originating from the inferior or lateral walls of the $\operatorname{sinus}^{5}$ (Fig. 1).

Maxillary sinus septa are varied in size and position, and different prevalence rates have been reported in various studies. ${ }^{6-8}$ Septa might be detected in 9 to $70 \%$ (a mean of $36 \%$ ) of patients. ${ }^{9}$ Panoramic radiographs are not reliable in this context because they yield false-positive

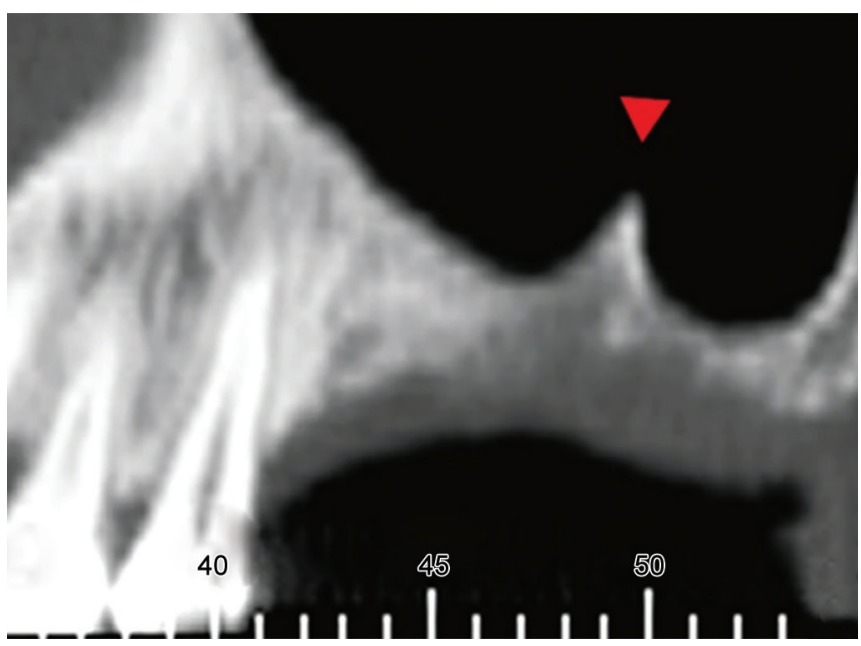

Fig. 1: Septa originating from the inferior wall of sinus 
results of the presence of septa in 11.8 to $52.68 \%$ of the cases. ${ }^{10}$ Based on the latest guidelines of the European Association of Osseointegration and the International Team for Implantology, three-dimensional (3D) imaging techniques, such as computed tomography (CT) and cone beam computed tomography (CBCT) are preferable for such evaluations. ${ }^{11}$ In this context, an accurate imaging technique, i.e., able to provide a 3D view of the anatomy of the maxillary sinus will be very useful. ${ }^{11}$ The CBCT is a medical imaging technique that uses $\mathrm{X}$-rays to provide images. ${ }^{12}$ During the imaging procedure, the scanner of the machine revolves around the patient's head and provides approximately 600 diagnostic images, which are reconstructed by the software program of the machine. These images can be used to evaluate each area from different and unique angles. ${ }^{13,14}$ The CBCT technique was introduced to the dental field in the late 1990s. ${ }^{15,16}$ One of the most important advantages of CBCT is a decrease in the patient radiation dose. ${ }^{17-19}$

It is very important to observe and identify septa before sinus lift procedures because designing of the lateral window during the sinus lift procedure depends on the presence and height of these septa. Therefore, the aim of the present study was to determine the prevalence, position, and size of maxillary sinus septa, using the $\mathrm{CBCT}$ imaging technique, in a population of Iranian subjects for the placement of implants in the posterior maxilla.

\section{MATERIALS AND METHODS}

The present descriptive retrospective study was carried out in the Department of Periodontics, Shahed University, during 2014-2015. The protocol of the study was approved by the Ethics Committee of Shahed University. The digital images were taken by a CBCT unit (Newtom VG, Verona, Italy) using the following exposure conditions: $\mathrm{kVp}=110, \mathrm{~mA}=4.08-6.09, t=3.6$ seconds, field of view $=160 \times 110 \mathrm{~cm}$, voxel size of $0.3 \mathrm{~mm}$ for full and $0.25 \mathrm{~mm}$ for zoom, and slice thickness $=1 \mathrm{~mm}$.

A total of 300 CBCT images of 138 females and 162 males, with an age range of 33 to 86 years, were retrieved from the archives of a specialty radiology center; they had been referred to the clinic in 2014-2015. All the CBCT images had been taken in order to place dental implants. The images were selected randomly based on inclusion criteria, which consisted of the following: (1) CBCT images of posterior maxilla when upper molars and premolars are absent at least on one side; (2) visibility of at least $2 \mathrm{~cm}$ above the sinus floor; and (3) no motion or scattering artifacts. Images exhibiting changes in the morphology of sinus walls due to trauma or pathologic conditions were excluded from the study.
The maxillary sinus septa were evaluated on the coronal cross-sections with the use of the quantitative radiology software program (NNT Workstation, Version 4.5, Verona, Italy). Data were recorded in special forms for each patient.

The maxillary sinus septa were evaluated in relation to the following variables:

\section{Prevalence (in Terms of Gender, Age, and the Type of the Residual Ridge)}

The type of the residual ridge was evaluated based on a classification introduced by Lekhom and Zarb ${ }^{32}$ in terms of the amount of resorption in the edentulous area: (A) Ridges with no signs of atrophy; (B) ridges with some atrophy, with adequate ridge width and a small amount of decrease in ridge height; (C) advanced ridge atrophy, with decreases in both the width and height of the ridge; (D) severe atrophy of the ridge with severe decreases in the height and width of the ridge; and (E) complete atrophy of the ridge.

\section{Position}

In order to evaluate the position of the septa, the sinus floor was divided into three segments: Anterior, middle, and posterior. In the present study, since all the patients were edentulous, the positions of the teeth were estimated by a software program.

In order to classify septa location, the antral cavity was divided into three regions according to the protocol by Kim et al: Anterior (mesial to the distal aspect of the 2nd premolar), middle (distal to the 2nd premolar to distal of the 2nd molar), and posterior (mesial to the distal aspect of the 3 rd molar). ${ }^{20}$

\section{Height}

The height of the sinus was also evaluated. In addition, the patients were divided into two groups - partially and completely edentulous. The images were evaluated by a trained observer.

All measurements were taken twice by the same observer at an interval of 2 weeks.

\section{Statistical Analysis}

Statistical analyses were carried out using the Statistical Package for the Social Sciences (SPSS) software program (Version 22.0, Armonk, NV:IBM Cor, USA). Significance was accepted at $\mathrm{p}<0.05$.

Descriptive statistics (means, variance, standard deviations, and change ranges) were used for the analysis of data. The $\mathrm{t}$-test was $\mathrm{u}$ sed to compare the means between the two groups with the use of quantitative data 
and the relative measurement scale; Mann-Whitney and Kruskal-Wallis nonparametric tests were used to compare the means between the two groups with the use of qualitative data and ordinal measurement scale.

\section{RESULTS}

The mean age of the subjects was $62.4 \pm 10.6$ years, with a range of 33 to 86 years. The results of the study showed that septa were present in $44 \%$ of the sinuses, with no significant differences in the presence and observance of septa between males and females ( $p>0.05)$ (Table 1).

In subjects exhibiting septa, the septa were detected in the posterior, middle, and anterior areas of maxillary sinuses in $32.6,34.8$, and $52.6 \%$ of the cases respectively, with no significant difference between males and females (p > 0.05) (Table 2).

The mean height of the septa was $3.67 \pm 1.56 \mathrm{~mm}$ in males and females. Based on the results of the t-test, there was a significant difference in the mean heights of septa between males and females $(p=0.006)$. The mean heights of septa were $4.08 \pm 1.64$ and $3.33 \pm 1.42 \mathrm{~mm}$ in males and females respectively $(\mathrm{p}<0.01)$ (Table 3$)$.

Based on the classification given by Zarb and Lekhom, the majority of the subjects in the present study had ridges in the C (53\%) and D (335\%) categories (Table 4).

The results of Kruskal-Wallis test did not show any relationship between the type of the edentulous ridge and the prevalence of septa $(p>0.05)$.

In addition, the results of the Mann-Whitney test showed no relationship between the type of edentulism (complete or partial) and the prevalence of septa $(p>0.05)$.

Table 1: The prevalence of septa in terms of gender

\begin{tabular}{lllll}
\hline \multirow{2}{*}{ Gender } & Male & $\begin{array}{l}\text { Absence } \\
\text { of septa }\end{array}$ & $\begin{array}{l}\text { Presence } \\
\text { of septa }\end{array}$ & p-value \\
& Female & $78(56.5 \%)$ & $60(43.5 \%)$ & 0.867 \\
& $90(55.5 \%)$ & $72(44.5 \%)$ & \\
\hline
\end{tabular}

Table 2: The position of septa in terms of gender

\begin{tabular}{llllll}
\hline & & Posterior & Middle & Anterior & $p$-value \\
\hline \multirow{2}{*}{ Gender } & Male & $24(41.3 \%)$ & $16(27.6 \%)$ & $18(31.3 \%)$ & 0.189 \\
& Female & $19(25.7 \%)$ & $30(40.5 \%)$ & $25(33.8 \%)$ & \\
\hline
\end{tabular}

Table 3: The descriptive data of the heights of septa in terms of gender

\begin{tabular}{llllll}
\hline Gender & Min & Max & Mean & SD & SEM \\
\hline Male & 2.7 & 8.8 & 4.08 & 1.64 & 0.21 \\
Female & 1.5 & 7.6 & 3.33 & 1.42 & 0.17 \\
\hline
\end{tabular}

SD: Standard deviation; SEM: Standard error of the mean

Table 4: Evaluation of different types of residual ridges based on the classification of Zarb and Lekhom

\begin{tabular}{llllll}
\hline & $A$ & $B$ & $C$ & $D$ & $E$ \\
\hline Frequency (\%) & 1.5 & 8 & 53 & 33.5 & 4 \\
\hline
\end{tabular}

Pearson's correlation coefficient showed a correlation between age and the prevalence of septa $(p=0.001)$, with a decrease in their prevalence with aging.

\section{DISCUSSION}

Considering the changes in the volume and size of bone in the edentulous posterior maxilla due to the expansion of the maxillary sinus in association with the resorption of the alveolar bone, it is necessary to increase the volume and size of the bone in this area in order to place implants. ${ }^{21}$ The sinus lift procedure in this area is one of the best and safest methods to solve such a problem. ${ }^{1}$ Therefore, it is necessary for the surgeon to acquire proper knowledge about this area. The prevalence of septa can be calculated based on either the number of sinuses that have septa or the number of patients who have septa.

In the present study, almost half of the sinuses exhibited septa (44\%). Based on a systematic review in 2001 by Maestre-Ferrín et $\mathrm{al}^{22}$ in studies in which the prevalence of septa was expressed in terms of the number of sinuses, the prevalence of septa was 13 to $35.3 \%$, and in studies in which the prevalence of septa was reported in terms of the number of patients, the prevalence of septa was 21.6 to $66.7 \%$. Based on a systematic review by Malec et al in $2014,{ }^{9}$ septa were detected in 9 to $70 \%$ of the subjects in all the age groups, with a mean prevalence rate of $36 \%$. The prevalence rates of septa have been reported differently in different studies, depending on the type of edentulism (partial or complete), the patients being dentate, and the imaging technique used (CBCT, CT, or panoramic). Ilguly et $\mathrm{al}^{33}$ Maestre-Ferrín et ${ }^{31}{ }^{7}$ Malec et $\mathrm{al}^{23}{ }^{23}$ Qian et al, ${ }^{24}$ and Sakhdari et $\mathrm{al}^{25}$ reported rates of 55.2, 53.2, 49, 48.2 and $44.8 \%$ respectively, for the prevalence of sinus septa, almost consistent with the results of the present study. Based on a study by Faramarzie et al, ${ }^{26}$ the sequence of tooth extraction might affect the position of septa in the maxillary sinus.

Septa were detected in the three posterior (32.6\%), middle $(34.8 \%)$, and anterior $(32.6 \%)$ segments of the sinuses almost equally. In the study by Maestre-Ferrín et $\mathrm{al}^{7}$ septa were present in the middle, posterior, and anterior segments of the sinus in $60,22.5$, and $17.5 \%$ of the cases respectively. In a study by Kim et al, ${ }^{20}$ septa were found in 50.8 and $23.7 \%$ of the sinuses in the middle and posterior segments respectively. In studies by Pommer et $\mathrm{al}^{27}$ and Bornstein et $\mathrm{al}^{28}$ the most frequent positions of the septa were above the 1st and 2nd maxillary molars. In a study by Shahidi et al, ${ }^{29}$ septa were present in the anterior, middle, and posterior segments of the sinuses in 58.9, 21.1 , and $20 \%$ of the cases respectively. Such a discrepancy between the results might be attributed to individual differences and minor differences in dividing the sinuses into 
anterior, middle, and posterior segments. In relation to the position of septa, there were no significant differences between males and females in the present study, consistent with the results reported by Maestre-Ferrín et al. ${ }^{7}$

In the present study, the mean height of septa was 3.67 $\pm 1.56 \mathrm{~mm}$ (with a range of 1.5-8.8 mm). Different studies have reported different heights for septa. ${ }^{9}$ Qian et $\mathrm{al}^{24}$ reported mean heights of $6.44,5.56$, and $4.39 \mathrm{~mm}$ in the medial, middle, and lateral areas of the sinuses respectively. In a study by Sakhdari et al, ${ }^{25}$ the mean height of septa on the right side was $6.3 \mathrm{~mm}$, with $7.1 \mathrm{~mm}$ on the left side. In a study by Naitoh et $\mathrm{al}^{30}$ too, the mean height of septa was reported to be $3 \mathrm{~mm}$, almost consistent with the present study.

The results of the present study showed no relationship between the type of edentulism (complete and partial) and the prevalence of septa, consistent with the results of a study by Qian et al. ${ }^{24}$ Some studies have reported a higher prevalence of septa in totally edentulous subjects compared with partially edentulous subjects, which was attributed by Kim et $\mathrm{al}^{20}$ to the fact that atrophic edentulous maxilla generally contains secondary septa. ${ }^{31}$

\section{CONCLUSION}

Based on the results of the present study, $44 \%$ of the maxillary sinuses had septa. In order to avoid intraoperative problems during sinus lift procedures, it is necessary to accurately evaluate the sinus, preferably with the use of CBCT.

\section{REFERENCES}

1. Pjetursson BE, Tan WC, Zwahlen M, Lang NP. A systematic review of the success of sinus floor elevation and survival of implants inserted in combination with sinus floor elevation. J Clin Periodontol 2008 Sep 1;35(Suppl 8):216-240.

2. Kang SJ, Shin SI, Herr Y, Kwon YH, Kim GT, Chung JH. Anatomical structures in the maxillary sinus related to lateral sinus elevation: a cone beam computed tomographic analysis. Clin Oral Implants Res 2013 Aug 1;24(A100):75-81.

3. Testori T, Wallace SS, Del Fabbro M, Taschieri S, Trisi P, Capelli M, Weinstein RL. Repair of large sinus membrane perforations using stabilized collagen barrier membranes: surgical techniques with histologic and radiographic evidence of success. Int J Periodontics Restorative Dent 2008 Feb;28(1):9-17.

4. Underwood AS. An inquiry into the anatomy and pathology of the maxillary sinus. J Anat Physiol 1910 Jul;44(Pt 4):354.

5. Bergh J, Bruggenkate CM, Disch FJ, Tuinzing DB. Anatomical aspects of sinus floor elevations. Clin Oral Implants Res 2000 Jun 1;11(3):256-265.

6. Kasabah S, Slezák R, Simunek A, Krug J, Lecaro MC. Evaluation of the accuracy of panoramic radiograph in the definition of maxillary sinus septa. Acta Medica (Hradec Kralove) 2002;45(4):173-176.

7. Maestre-Ferrín L, Carrillo-García C, Galán-Gil S, PeñarrochaDiago M, Peñarrocha-Diago M. Prevalence, location, and size of maxillary sinus septa: panoramic radiograph versus computed tomography scan. J Oral Maxillofac Surg 2011 Feb 28;69(2):507-511.

8. Velásquez-Plata D, Hovey LR, Peach CC, Alder ME. Maxillary sinus septa: a 3-dimensional computerized tomographic scan analysis. Int J Oral Maxillofac Implants 2002 Nov 1;17(6): 854-860.

9. Malec M, Smektała T, Trybek G, Sporniak-Tutak K. Maxillary sinus septa: prevalence, morphology, diagnostics and implantological implications. Systematic review. Folia Morphol 2014 Aug 1;73(3):259-266.

10. Ella B, Noble RD, Lauverjat $Y$, Sédarat C, Zwetyenga N, Siberchicot F, Caix P. Septa within the sinus: effect on elevation of the sinus floor. Br J Oral Maxillofac Surg 2008 Sep 30;46(6):464-467.

11. Bornstein MM, Scarfe WC, Vaughn VM, Jacobs R. Cone beam computed tomography in implant dentistry: a systematic review focusing on guidelines, indications, and radiation dose risks. Int J Oral Maxillofac Implants 2014 Jan 2;29 Suppl:55-77.

12. Scarfe WC, Farman AG, Sukovic P. Clinical applications of cone-beam computed tomography in dental practice. J Canad Dent Assoc 2006 Feb 1;72(1):75.

13. Hatcher DC. Operational principles for cone-beam computed tomography. J Am Dent Assoc 2010 Oct 31;141:3S-6S.

14. Orth RC, Wallace MJ, Kuo MD. Technology assessment committee of the society of interventional radiology. C-arm cone-beam CT: general principles and technical considerations for use in interventional radiology. J Vasc Intervent Radiol 2008 Jun 30;19(6):814-820.

15. Arai Y, Tammisalo E, Iwai K, Hashimoto K, Shinoda K. Development of a compact computed tomographic apparatus for dental use. Dentomaxillofac Radiol 1999 Jul;28(4): 245-248.

16. Mozzo P, Procacci C, Tacconi A, Martini PT, Andreis IB. A new volumetric CT machine for dental imaging based on the cone-beam technique: preliminary results. Eur Radiol 1998 Nov 1;8(9):1558-1564.

17. Ludlow JB, Ivanovic M. Comparative dosimetry of dental CBCT devices and 64-slice CT for oral and maxillofacial radiology. Oral Surg Oral Med Oral Pathol Oral Radiol Endod 2008 Jul 31;106(1):106-114.

18. White SC, Mallya SM. Update on the biological effects of ionizing radiation, relative dose factors and radiation hygiene. Austral Dent J 2012 Mar 1;57(s1):2-8.

19. White SC, Pharoah MJ. Oral radiology: principles and interpretation. Elsevier Health Sciences; 2014 May 1.

20. Kim MJ, Jung UW, Kim CS, Kim KD, Choi SH, Kim CK, Cho KS. Maxillary sinus septa: prevalence, height, location, and morphology. A reformatted computed tomography scan analysis. J Periodontol 2006 May;77(5):903-908.

21. Newman MG, Takei H, Klokkevold PR, Carranza FA. Carranza's clinical periodontology. Elsevier Health Sciences; 2011 Feb 14.

22. Maestre-Ferrín L, Galán-Gil S, Rubio-Serrano M, PeñarrochaDiago M, Peñarrocha-Oltra D. Maxillary sinus septa: a systematic review. Med Oral Patol Oral Cir Bucal 2010 Mar 1; 15(2):383-386.

23. Malec M, Smektala T, Tutak M, Trybek G, Sporniak-Tutak K, Malec M, Smektala T, Tutak M, Trybek G, Sporniak-Tutak K. Maxillary sinus septa prevalence and morphology - computed tomography based analysis. Int J Morphol 2015 Mar 1;33(1): 144-148. 
24. Qian L, Tian XM, Zeng L, Gong Y, Wei B. Analysis of the morphology of maxillary sinus septa on reconstructed conebeam computed tomography images. J Oral Maxillofac Surg 2016 Apr 30;74(4):729-737.

25. Sakhdari S, Panjnoush M, Eyvazlou A, Niktash A. Determination of the prevalence, height, and location of the maxillary sinus septa using cone beam computed tomography. Implant Dent 2016 Jun 1;25(3):335-340.

26. Faramarzie M, Babaloo AR, Ghertasi Oskouei S. Prevalence, height, and location of antral septa in Iranian patients undergoing maxillary sinus lift. J Periodontol Implant Dent 2009 Mar 12;1(1):43-47.

27. Pommer B, Ulm C, Lorenzoni M, Palmer R, Watzek G, Zechner W. Prevalence, location and morphology of maxillary sinus septa: systematic review and meta-analysis. J Clin Periodontol 2012 Aug 1;39(8):769-773.

28. Bornstein MM, Seiffert C, Maestre-Ferrín L, Fodich I, Jacobs R, Buser D, von Arx T. An analysis of frequency, morphology, and locations of maxillary sinus septa using cone beam computed tomography. Int J Oral Maxillofac Implants 2016 Mar-Apr;31(2):280-287.

29. Shahidi S, Zamiri B, Danaei SM, Salehi S, Hamedani S. Evaluation of anatomic variations in maxillary sinus with the aid of cone beam computed tomography (CBCT) in a population in south of Iran. J Dent 2016 Mar;17(1):7.

30. Naitoh M, Suenaga Y, Kondo S, Gotoh K, Ariji E. Assessment of maxillary sinus septa using cone-beam computed tomography: etiological consideration. Clin Implant Dent Relat Res 2009;11(s1):e52-e58.

31. Krennmair G, Ulm CW, Lugmayr H, Solar P. The incidence, location, and height of maxillary sinus septa in the edentulous and dentate maxilla. J Oral Maxillofac Surg 1999 Jun 30; 57(6):667-671.

32. Lekholm U. Patient selection and preparation. Tissue-integrated prosthesis: osseointegration in clinical dentistry. 1985:199-209.

33. Ilguy D, Ilguy M, Dolekoglu S, Fisekcioglu E. Evaluation of the posterior superior alveolar artery and the maxillary sinus with CBCT. Brazilian Oral Res 2013;27(5):431-437. 